\title{
IYL 2015 celebrations
}

\section{Aaron Morgan Adams, Gary Beasley}

Aaron Morgan Adams, Gary Beasley, "IYL 2015 celebrations," Proc. SPIE 9946, Optics Education and Outreach IV, 99460A (27 September 2016); doi: $10.1117 / 12.2236744$

SPIE Event: SPIE Optical Engineering + Applications, 2016, San Diego, California, SPIE. United States 


\title{
IYL 2015 Celebrations
}

\author{
Aaron Morgan Adams, Gary Beasley \\ Central Carolina Community College, 1075 E. Cornelius Harnett Blvd., Lillington, NC 27546; \\ Indian River State College / LASER-TEC / Southeast Regional Center for Laser \& Fiber Optics \\ Education, 3209 Virginia Avenue, Fort Pierce, FL 34981
}

\begin{abstract}
The International Year of Light 2015 was designed to raise awareness of light sciences. In order to raise awareness, events were encouraged to get the public involved. Both Central Carolina Community College (CCCC) and Indian River State College (IRSC) held a total of three lectures in 2015 celebrating the IYL 2015.

IRSC hosted lectures on March 6th and June 11th. CCCC hosted a lecture on November 17th. These lectures drew a total of over 400 attendees. Lectures revolved around their own unique themes relating to light sciences in industry and academia. With great support from Laser-Tec, SPIE, and NSF, these lectures were successful at exposing and advertising the optics field to the public, as well as promising up-and-coming students.

These lectures hosted several keynote speakers on behalf of both industry and academia. The speakers were successful at keeping the audience engaged through presentations and Q\&A sessions. In addition, lab tours allowed the attendees a chance to see the programs in action.

Many takeaways will prove to be invaluable when pursuing such events in the future. This paper will not only speak to the tremendous success of these lectures, but will take an honest look at the areas for improvement. It is important to note that independent events can be held for the expansion of local programs leading to national, if not global, increase in communal awareness and participation. These events will serve as a continuation for what the IYL 2015 was designed.
\end{abstract}

Keywords: Central Carolina Community College, CCCC, Indian River State College, IRSC, LASER-TEC, Q\&A, International Year of Light 2015, IYL 2015

\section{ORIGIN}

The populace tends to overlook the impact that light has on everyday life. Whether a desk lamp, a traffic signal, or the sun, sources of light are heavily utilized and rarely fully comprehended. It is easy to understand the purpose for which light is used, however, grasping how light becomes usable is often taken for granted. While lacking an in-depth knowledge may not be detrimental, underappreciating its genesis will certainly slow progression and utilization. The United Nations (UN) not only wanted to inform the public, they wished to celebrate this precious resource. The year 2015 was declared as the International Year of Light and Light-based Technologies (IYL 2015). This declaration was made to create a global rejoice.

By taking a moment to step back and appreciate light and the relating technologies, the world would become more aware of the opportunities of the day and the future. This would be accomplished through several ways, including having educational institutes to host their own IYL 2015 Celebrations. Indian River State College (IRSC), home of the Southeast Regional Center for Laser and Fiber Optics Education (LASER-TEC), and Central Carolina Community College (CCCC) took the opportunity to join in the celebrations.

This was a chance participate in a global intuitive through local engagement. At bare minimum, it would be an opportunity to connect with the community about the educational services that are offered. An opportunity to get students, from the very young to the well-seasoned, excited about being able to continuously improve their life and the lives of those around them.

Optics Education and Outreach IV, edited by G. Groot Gregory, Proc. of SPIE Vol. 9946, 99460A

(C) 2016 SPIE $\cdot$ CCC code: $0277-786 \mathrm{X} / 16 / \$ 18 \cdot$ doi: $10.1117 / 12.2236744$ 


\section{ORGANIZATION}

A lot of people, departments, and sponsors joined to make celebrations possible. As with any event, a great deal of planning was needed to ensure a successful campaign. Both Indian River State College (IRSC) and Central Carolina Community College (CCCC) initiated celebrations internally. This presented a beneficial opportunity for both the schools and as well as the attending public.

A typical campus will have a designated area within its walls that is hospitable for hosting a public event. The two events at IRSC were held in the Kight Center for Emerging Technologies. This allowed for the use of a large lecture hall for presentations. The center also has a large atrium-style lobby where booths and demonstrations could be staged. The satellite campus for CCCC that houses the Laser and Photonics Technology Program (LPT) is a good deal smaller than its main campus. In order to allow for some hands-on interaction, CCCC chose to use a simple multipurpose room. Whether large or small, any college campus would likely have some allotted space for a public presentations. This could have the advantage of requiring nothing more than a simple room reservation.

Colleges also possess the ability to turn to in-house marketing, multimedia, and communication specialists. Both IRSC and CCCC were able to market and advertise the celebrations as a part of the day to day activity. A few phone calls and emails allowed for a group collaboration on what would be the ideal steps to take. The celebration sparked from a teleconference with Ms. Natalia Chekhovskaya Kearney, the Program Director for IRSC and LASER-TEC. Given Ms. Kearney's wealth of knowledge and collaboration with the IRSC celebrations, she proved to be an invaluable source of information about where to begin.

For instance, the event at CCCC began with a simple email to Ms. Marcie Dishman, the Associate Vice President of Marketing and Human Resources. She immediately recommended bringing in Mr. Neil McGowan, a Graphic Artist \& Multimedia Specialist, as well as Mr. R.V. Hight, the Director of Communications. With these continuous exchanges, CCCC was able to facilitate responsibilities among subject-matter experts. These professionals quickly took ownership. Everyone took it upon themselves to contribute their time and energy to the project.

Although this was primarily a LPT project, all of these specialist quickly realized how beneficial this celebration would be for the school and the community. Ms. Dishman was able to bring in her previous experience with school events. Ms. Dishman went as far as to offer CCCC merchandise bags for the hand-out of literature and mementos for the attendees. Mr. McGowan was made himself readily available to perfect the design and implementation of flyers, program guides, and t-shirts. Mr. Hight provided entertaining and enlightening articles to news outlets, both within the school as well as external media sources. All of these professionals offering their skills ensured a successful celebration.

Another invaluable asset that a college will usually possess is a great maintenance department. Mr. Chris McNeill, the Maintenance Supervisor for this particular CCCC satellite campus, offered great assistance with his team. Due to Mr. McNeill's diligence, his team was able to set-up the room with enough seating and educational posters and banners for the event. The team quickly returned the room to its original state after the proceedings.

With the locations being declared, the next step was to find speakers for the celebrations. Both IRSC and CCCC reached out to employers of graduates, local and federal agencies, in addition to instructors of light sciences. Those whom were able to attend, were generally excited to take part in the celebrations. The presentations would prove to be both enlightening and entertaining to a public that has little or no knowledge of these sciences.

A good deal of the educational material for the celebrations were provided by SPIE. With the help of Ms. Pascale Barnett, Ms. Debra Joslyn, and Ms. Karen Rollo, IRSC and CCCC were able to receive very informative and entertaining material to give away. This material cost no more than the postage needed for transport. Materials included flashlights, posters, pens, and many other items that set the tone for the events. In addition to SPIE, the National Science Foundation (NSF) and LASER-TEC provided great resources and materials to host the events. Again, this demonstrated great teamwork and vision to raise the awareness for which the IYL 2015 Celebrations sought to raise.

A majority of the leg work was completed by another great internal asset, the program students. These students, from both the past and present, wanted the celebration to be a success. This presence will prove to be irreplaceable. The 
students represented their programs with the upmost excitement and integrity. Any last minute changes or improvements were placed in the students' hands. It was important for the programs to take ownership of the project. From stuffing bags of souvenirs to handing out raffle tickets, the program students understood that they had a lot to offer to the project.

To maintain the "celebration" aspect of the event, everyone agreed that raffle tickets and contest prizes would be fun to have for the community. Local restaurants were approached for assistance. Even though IRSC and CCCC were wanting to purchase gift certificates, many simply offered them for no cost. Their generosity was well received and displayed strong community involvement. In addition to local eateries, programs within the school offered to provide prizes. For instance, the Cosmetology Department at CCCC provided certificates for haircuts, and other beauty services they offered. Writing contest winners were rewarded with Light and Optics Exploration Kits from LASER-TEC. Everyone that had anything to offer, did so freely and passionately.

\section{CELEBRATIONS}

Indian River State College (IRSC) hosted two events in 2015. The first on March $6^{\text {th }}$ (Shedding Light on Laser and IR Technologies) and the second on June $11^{\text {th }}$ (The Unlimited Power of Photonics and Light). Central Carolina Community College (CCCC) hosted its own event on November $17^{\text {th }}$ (Helping to Bring My Dream to Light). These three combined gained a crowd of over four-hundred in attendance. In addition these celebrations, LASER-TEC, based at IRSC, joined in the "Wonders of Light" IYL event. This event was held on September $12^{\text {th }}$ at the National Museum of the American Indian in Washington DC. This event itself drew more than five-hundred attendees. IYL 2015 Celebrations revolved around an individual theme unique to the celebration itself. Although the themes varied among these celebrations, the purpose and implementation were very similar.

There was no fee for the public to attend these events. This proved to be advantageous for the fact that not everyone in attendance would have been able to participate in the IYL 2015 Celebrations. Due to the welcoming feel of the celebrations, a wide range of the community attended. This allowed for greater exposure and awareness of light science and technologies. Parents attended with their children. Adults attended with friends. The room was filled with future students and scientist. This alone marked the event as a success.

All events featured keynote speakers. The keynote ranged from industry, to academia, as well as government supported organizations. The two celebrations events hosted by IRSC included Dr. Richard DeSalvo, Senior Scientist at Harris Corporation's Photonics Center, and Justin Jensen, IRSC graduate and Project Engineer with Laser Components Pyro Group. The presentation by Dr. DeSalvo revolved around lasers and their applications. In addition, Mr. Jensen presented infrared technology and applications.

The celebration at CCCC included educators such as Mr. Bill Tyson, the Provost of this particular CCCC campus. Mr. Tyson welcomed all guest in attendance. In addition, Mr. Gary Beasley, the Lead Instructor of Laser and Photonics Technology Program (LPT), introduced all of the keynote speakers. In addition, Mr. Beasley provided great insight on the LPT Program. CCCC was fortunate to have Ms. Natalia Chekhovskaya Kearney on-site to express LASER-TEC's role in education as well as employment outlook in the field. Presentations were given several experts from industry, including Mr. Ron Darbee, the Division Superintendent of the National Ignition Facility (NIF) at Lawrence Livermore National Laboratory. Very few in the audience had ever heard a presentation about nuclear fusion. After which, Mr. Scott Hamlin, the President of MegaWatt Lasers, impressed the attendees with his companies pioneering advancements with diode lasers. The next presenter, Mr. Joel Sigmund, Market Segment Manager at Disco Hi-Tec America, shared some of the cutting-edge products and services that his company offers. The crowd was also introduced to crystal growth from Dr. Kevin Stevens, the Director of Research and Development at Northrop Grumman - SYNOPTICS. These presenters left the audience curious to learn more. Q\&A sessions followed the presentations. Questions ranged from areas of studies to opportunities for employment in the field. The excitement from the public seemed genuine and not just courteous.

The crowd really enjoyed the announcements of the raffle and contest winners. Every middle and high school student who entered in the writing contest won a LASER-TEC kit. The winners could not keep from smiling during a group picture. The raffle drawing winners were no less excited. With prizes alternating between pedicures and pizzas, from 
manicures to hardbound SPIE books, the event became a true celebration. Laughs, cheers, and applauses erupted as the next winner was announced. Adults and children alike seemed to fully appreciate the purpose of these events. The public was anxious to take part in tours to get more hands-on with the subject matter.

Following the CCCC event, the upcoming LPT graduates led groups around the labs. Using the on-site laser engraver, some of the attendees were treated to specialized name tags. Some labs included small scale light shows. Every lab demonstrated an aspect of what these programs had to offer. The crowd interacted with the instructors, students, and professionals alike. The speakers and event assistants were more than happy to accommodate any questions or suggestions about the field, the school, or the program itself.

\section{TAKEAWAYS}

There is always room for improvement with any project. Sadly, the most recognizable moments come in hindsight. This is no different when regarding the IYL 2015 Celebrations. There was no specific outline for how to celebrate light. Every host was given a unique opportunity to make each event their own. As with the three events hosted by Indian River State College (IRSC) and Central Carolina Community College (CCCC), all the lessons-learned from the first event were recorded and used to improve the upcoming event.

From the very first event, the biggest hurdle was getting people to show. Primarily, this was related to the amount of advertisement for the event. According to Ms. Natalia Chekhovskaya Kearney, "the event has to be advertised to onethousand people in order to get one-hundred to attend." With IRSC's second event, the decision was made to broadcast the event over the radio in real-time. This created an opportunity for those who may not have known about, or able to attend, a celebration. CCCC learned from this and relied heavily on Mr. R.V. Hight, the Director of Communications. Mr. Hight explored every option at his disposal. He was successful to say the least. Even though the areas within reach of the school is rather small, CCCC had over one-hundred community members attend. For future events, it may be beneficial to create social-media pages and announcements.

Another hurdle for a successful event would be finding the best night of the week. As with IRSC's first event, weekend nights proved more difficult to draw a larger crowd. This led to either Tuesday or Thursday evening sessions. Having the celebrations on a week-day night limited each events duration. IRSC and CCCC events were limited to two hours. Every one of these events ended before $8: 30 \mathrm{pm}$. This allowed for the attendees to return home at a reasonable hour.

The prizes and hand-outs were a success as expected. This proved that there are creative ways to add an air of whimsy to an event. For future events, IRSC and CCCC could offer custom engravings for winners. The schools can also look at more programs within to find opportunities as with CCCC's Cosmetology Department. Prizes do not have to cost an arm and leg. The crowd at these celebrations responded the same to a free poster as they did to a one-hundred dollar kit.

Future events should focus on attracting more school teachers in the area. Teachers are constantly looking for opportunities for their students to engage in learning outside the classroom. These teachers also have the ability to advertise the event to friends, family, as well as the parents of their pupils. In addition to public and private schools, home-school teachers should be addressed as well. Several school-aged children in attendance were home-schooled. Every teacher was allowed a first pick at the posters provided by SPIE. Next time, more prizes will be geared towards educators.

The tours and presentations were really the heart of the celebrations. With the goal being to raise awareness, the community gained no greater knowledge than that from the speakers and guides. Experiencing real world professionalism and hands-on demonstrations, the attendees witnessed a small portion of what is possible. Having thoughtful and relevant topics are crucial to keep the crowd engaged. Some of the feedback from the CCCC tour included the want for more time to spend in each lab. The tours were scheduled to keep the celebration within its twohour time allotment. Many of the public stayed later than expected in order to see more of this technology in action. CCCC instructors and students were more than happy to devote an extra fifteen minutes to allow the attendees to have all of their questions answered. 


\section{CONCLUSION}

The celebrations hosted by Indian River State College (IRSC) and Central Carolina Community College (CCCC) were successful. The events raised awareness for light and light-based technologies. IRSC and CCCC were able to open their doors and invite the community in for a chance to learn and participate. All in attendance, whether child or adult, appeared excited and entertained. As the celebrations continued, the crowd became more engaged. A lot of questions were asked and answered during the celebration. It is safe to say that everyone left with more knowledge than when they arrived. It is extremely important to keep that momentum going.

Moving forward, with the positive response from the IYL 2015 Celebration attendees, IRSC and CCCC will be hosting more events. Even though the events may not fall under the umbrella of the International Year of Light, they will still be celebrations. These events will be a chance for the public to experience all that IRSC and CCCC have to offer. The SPIE student chapter at CCCC is committed to hosting future events for the Laser and Photonics Technology Program. There is great opportunity for other programs, if not departments, to host such events.

If the public is shown a small portion of what an institute or field of study has to offer, then this should automatically stimulate curiosity. It may not be curiosity in a particular program or field, but a curiosity about finding an opportunity for continuous improvement. One could become curious about how to make their life, and the lives around them, better. This, by definition, would create growth and raise awareness. 


\section{MEDIA}

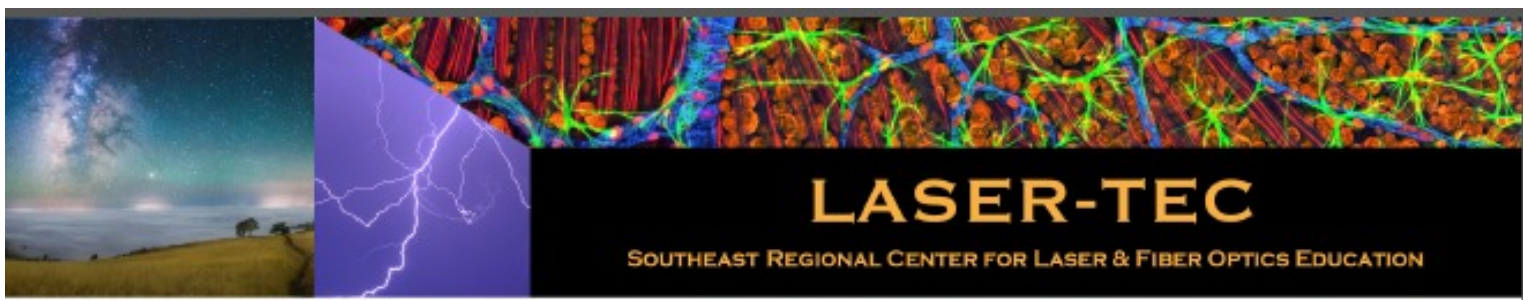

\section{SHEDDING LIGHT ON LASERS AND INFRARED TECHNOLOGIES}

\section{A free public event in celebration of the International Year of Light}

Friday, March 6, 2015

5:00 p.m. to 7:00 p.m.

\section{Indian River State College}

Main Campus

Kight Center for Emerging Technologies - V110

3209 Virginia Avenue • Fort Pierce, FL 34981

35th Street side of the campus

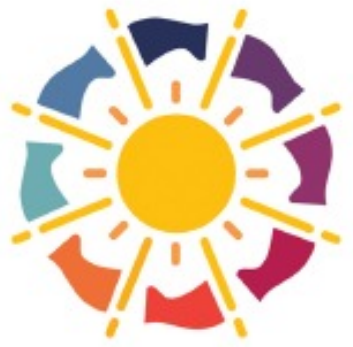

INTERNATIONAL YEAR OF LIGHT 2015

- Learn how lasers and infrared light technologies make our lives easier every day.

- Find out about IRSC programs and career opportunities in these fascinating technologies.

- Tours and demonstrations of amazing light technologies in the Photonics and Fiber Optics Labs.

Guest speakers spotlight the future of light technologies and the employment outlook.

Dr. Richard DeSalvo, Senior Scientist at Harnis Corporation's Photonics Center, Melbourne, FL

Addressing lasers and their applications

Justin Jensen, IRSC graduate and Project Engineer, Laser Components Pyro Group, Stuart, FL

Focusing on infrared technology and its applications

For more information email cpanayio@irsc.edu or call 772-462-7179

Registration preferred - Click Here

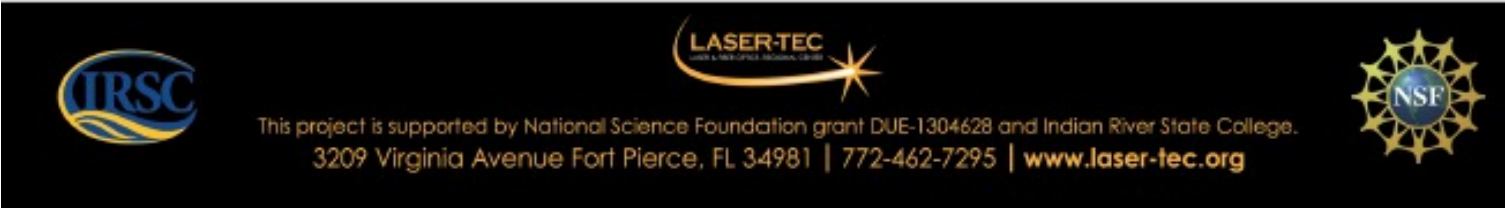

Flier: Event \#1, Indian River State College 


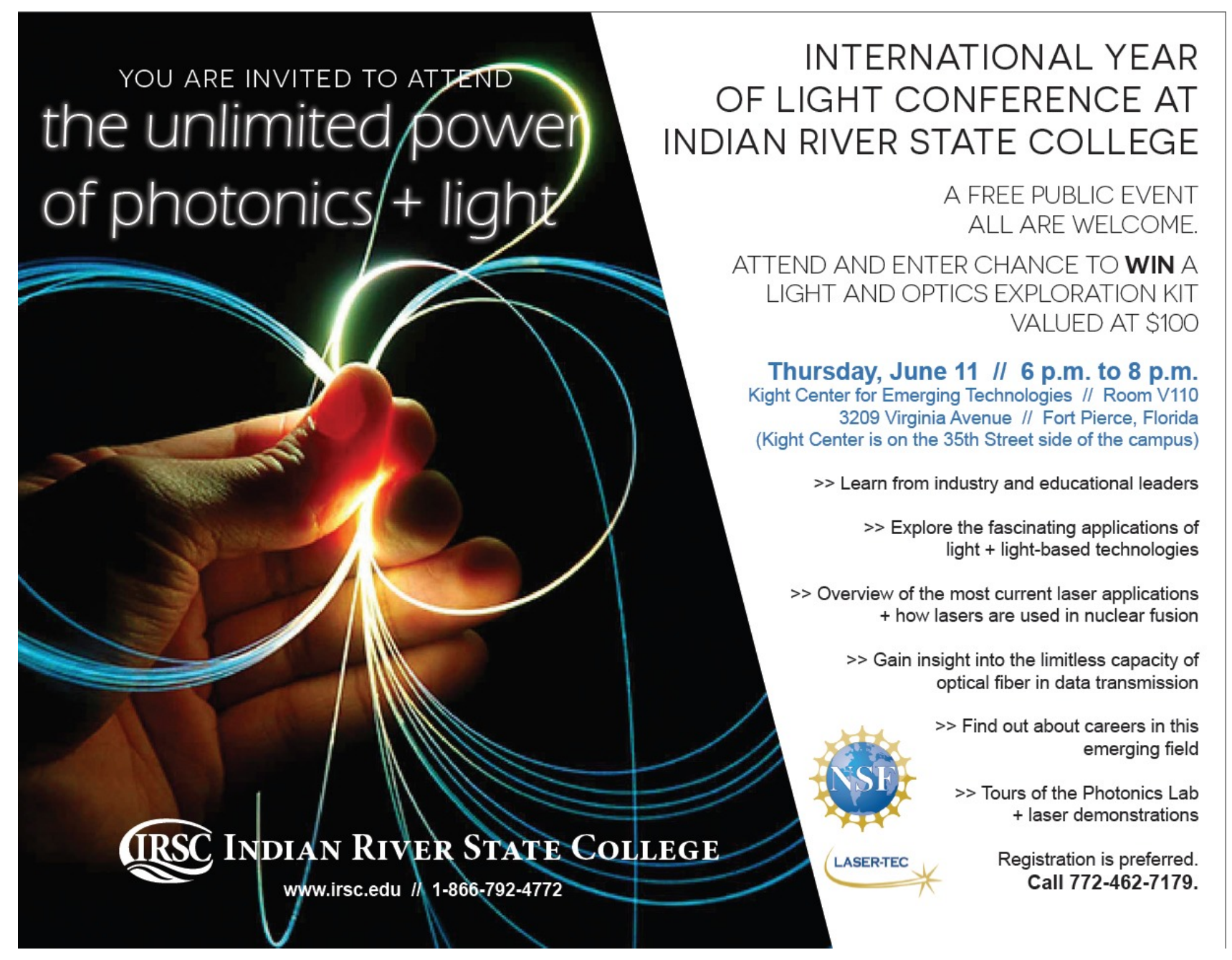

Flier: Event \#2, Indian River State College 

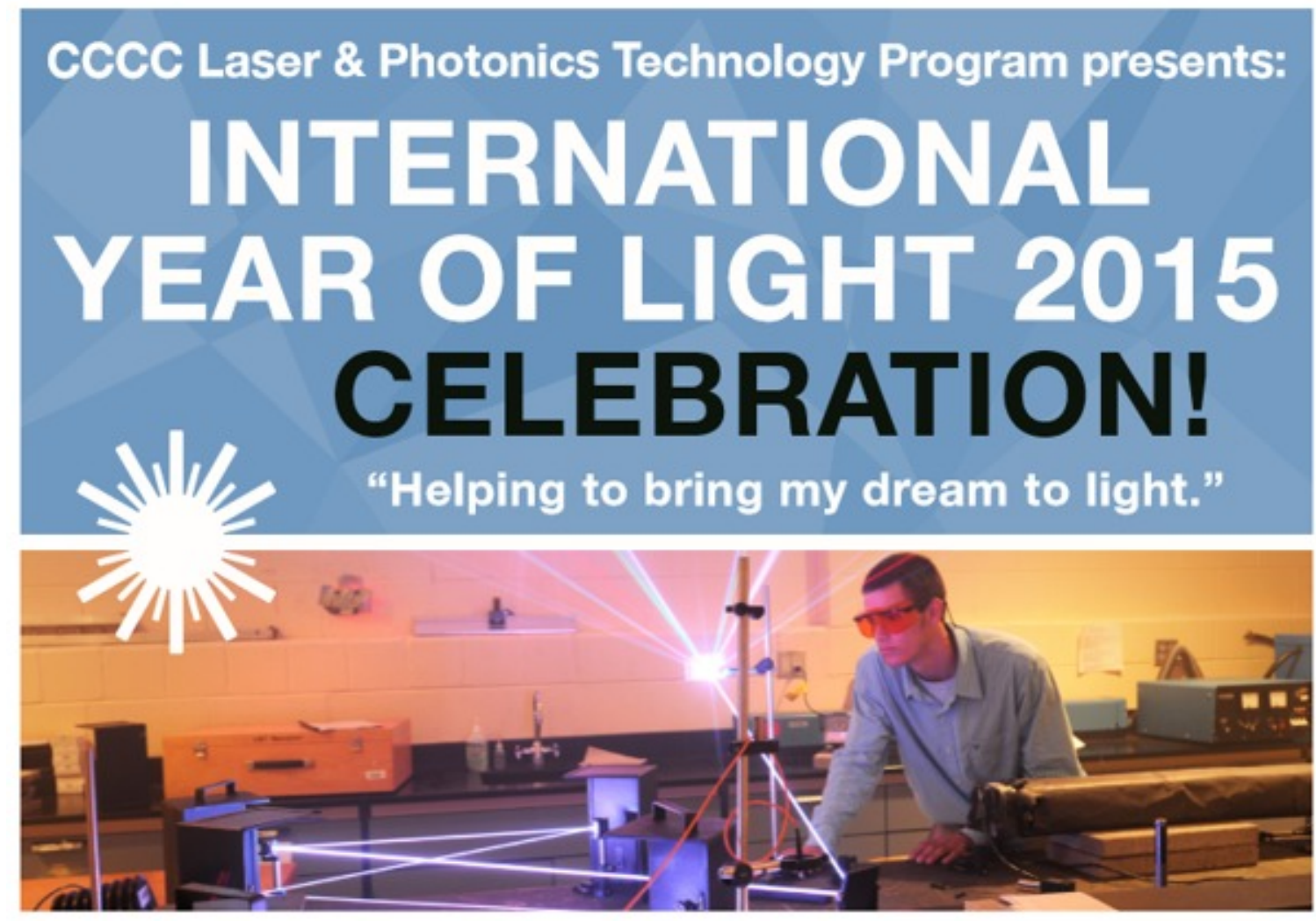

The United Nations proclaimed 2015 as the International Year of Light and Light-based Technologies.

Light Science and its applications promote sustainable development, and provide solutions to global challenges in energy, education, agriculture, and health.

\begin{tabular}{cc}
\hline - Guided tours and & - Door prizes \\
demonstrations & - Essay contests \\
- Keynote speakers & $\begin{array}{l}\text { (for Middle School and } \\
\text { High School students) }\end{array}$ \\
\hline
\end{tabular}

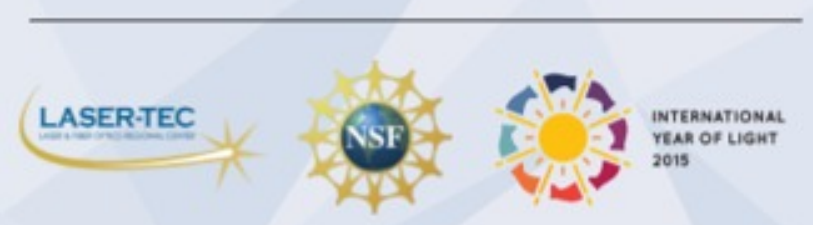

For more information, call (910) 814-8828 or email gbeasley@cccc.edu.

DATE:

November 17, 2015

\section{TIME:}

6:30 p.m. $-8: 30$ p.m.

\section{LOCATION:}

Harnett Campus

Miriello Bldg.

Multipurpose Rm. 135

1075 E. Cornelius Harnett Blvd.

Lillington, NC

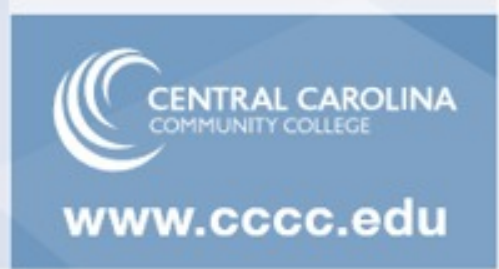

Flier: Event \#3, Central Carolina Community College 